\title{
Study on Mechanical Failure and PermeabilityCharacteristics of Porous Gas-Bearing Coal under Triaxial Stress
}

\author{
Xue-bo Zhang, ${ }^{1,2,3}$ Wen-yuan Wang $\mathbb{D}^{3}{ }^{3}$ Ming Yang, ${ }^{1,2,3}$ Hang-hang Cai, ${ }^{3}$ Jia-jia Liu, ${ }^{1,2,3}$ \\ and Shuai-shuai Shen ${ }^{3}$ \\ ${ }^{1}$ The Collaborative Innovation Center of Coal Safety Production of Henan Province, Jiaozuo, China \\ ${ }^{2}$ State Key Laboratory Cultivation Base for Gas Geology and Gas Control, Jiaozuo, China \\ ${ }^{3}$ College of Safety Science and Engineering, Henan Polytechnic University, Jiaozuo, China
}

Correspondence should be addressed to Wen-yuan Wang; 18332799635@163.com

Received 19 July 2020; Revised 20 August 2020; Accepted 16 September 2020; Published 19 October 2020

Academic Editor: Xianjie Hao

Copyright $(92020$ Xue-bo Zhang et al. This is an open access article distributed under the Creative Commons Attribution License, which permits unrestricted use, distribution, and reproduction in any medium, provided the original work is properly cited.

To explore the mechanical failure and permeability characteristics of porous gas-bearing coal under triaxial stress, the triaxial compression experiment was carried out for porous and conventional gas-bearing coal samples based on the triaxial creep-seepage experiment system and sound emission signal acquisition system. Acoustic emission testing was carried out at the same time of loading failure. The experimental results showed that (1) under fixed gas pressure but changing confining pressure, the porous gasbearing coal sample had higher peak strength and elastic modulus but lower peak strain; under changing gas pressure but fixed confining pressure, the porous gas-bearing coal sample had lower peak strength and peak strain but higher elastic modulus. When either confining pressure or gas pressure was changed, the mechanical properties of the two kinds of gas-bearing coal samples showed a good consistency, but the mechanical parameters differed greatly, with the peak strength, peak strain, and elastic modulus of porous coal samples are reduced by $1 / 4,2 / 3$, and $3 / 4$, respectively. (2) When either the confining pressure or gas pressure was changed, the permeability of the porous gas-bearing coal sample was larger than that of the conventional gas-bearing coal sample. However, the change rules of permeability characteristics of the two were basically the same, except that there was a large difference in permeability value that the porous gas-bearing coal sample increases nearly twice as much as that of the conventional gas-bearing coal sample. (3) In the whole stress-strain process, the acoustic emission characteristics of the porous gas-bearing coal sample differed significantly from those of the conventional gas-bearing coal sample. The maximum ringdown count of the porous gas-bearing coal sample can be reduced by one-third at most, the maximum energy can be reduced by nearly half at most, and the maximum amplitude changes little with only 1-3 dB reduction. The research results have important guiding significance for the prediction of failure and instability of coal tunnel and the development of relevant protective techniques.

\section{Introduction}

In recent years, China's coal demand has been high, and the depth of coal mining is increasing at a rate of $10-25 \mathrm{~m} / \mathrm{a}$, with the maximum mining depth exceeding $1500 \mathrm{~m}$ [1]. Deep coal has low permeability and high gas content, which is difficult to be extracted [2-4]. In the process of gas extraction, it is necessary to drill along the seam and through the seam, and in particular, the excavation of the outburst coal seam requires a lot of drilling. This has a certain impact on the stability of coal body. The study of mechanical failure and permeability characteristics of porous coal is of great significance to the study of coal tunnel stability and protection technology [5]. Many scholars at home and abroad have carried out a lot of theoretical, experimental, and numerical simulation studies on porous rock samples [6-8]. Tang et al. [9] conducted tests and numerical studies on the axial fracture failure characteristics of brittle materials with prefabricated holes under compression loading, and found that the initiation and propagation of cracks started from the tensile stress concentration area of holes. Shengqi et al. $[10,11]$ studied the influence of fracture dip angle on the 
mechanical properties of sandstone under uniaxial compression by using sandstone with pore fractures as research object, and studied the crack growth characteristics and its influence on the stress-strain curve of sandstone with combined defects of single fracture, double fracture, and circular holes using acoustic emission and digital photography. Zhaowei and Yuanhai [12] used digital photography to analyze the strain field and displacement field on the surface of porous marble. Long et al. [13] studied the influence of sample heterogeneity on crack growth direction and speed in sandstone specimens with pore-fracture combination defects under uniaxial compression, and pointed out that rock heterogeneity had a significant influence on secondary cracks and local growth speed of main cracks. Diyuan et al. [7] made plate-shaped specimen with bilateral prefabricated square holes by processing the iddefjord granite sample from Norway, carried out the uniaxial compression test, and carried out numerical simulation by FLAC ${ }^{3 \mathrm{D}}$. It was found that the splitting tensile crack always appears around the hole sample, and the shear failure zone gradually forms in the sample with the increase of load. Diyuan et al. [14] studied the dynamic compressive strength of marble with single holes under impact load and recorded the dynamic crack growth process of marble using high-speed camera, pointing out that under the action of impact load, the initiation and propagation of cracks started from the concentrated end of tensile stress and linked up with secondary cracks and far-field cracks, resulting in the final macroscopic failure of specimens. Saopeng et al. [15] observed the failure process and deformation field evolution characteristics of round hole structure of marble square plate with central round hole under uniaxial compression at a displacement loading speed of $0.02 \mathrm{~mm} / \mathrm{min}$. Yangsheng et al [16] studied the deformation law of borehole in granite body under constant temperature and pressure, carried out experimental research and theoretical analysis on its critical instability conditions and established the theoretical model of borehole deformation and viscoelastic and plastic theory model using the theory of viscoelastic and plastic mechanics. Zehong et al. [17] simulated the mechanical behavior of rocks containing boreholes, preliminarily mastered the mechanical properties of borehole instability in weak structures of deep coal under complex conditions, and established relevant numerical models.

It can be seen from the above studies that (1) most scholars use the uniaxial test to study, most scholars only carry out experiments on porous rock samples, and few scholars carry out comparative experiments on complete and porous rocks under triaxial stress. (2) In the study, the variation of various influencing factors on porous rock is not considered. To this end, this paper studies the influence of confining pressure or gas pressure change on mechanics, permeability, and acoustic emission characteristics of porous gas-bearing coal, as well as the difference of mechanics, permeability, and acoustic emission characteristics between porous and conventional gas-bearing coal samples under triaxial stress by using triaxial creep-seepage-adsorption and desorption experimental device.

\section{Sample Preparation and Experiment Scheme}

2.1. Sample Preparation. Coal blocks from 15-21030 mining face of Pingmei No. 8 mine in Henan Province were selected and made into several groups of raw coal samples in the laboratory. Then, boreholes which were $10 \mathrm{~mm}$ in diameter and $50 \mathrm{~mm}$ in length were drilled along the axial direction on the raw coal samples to make porous coal samples, which were numbered as shown in Figure 1. After that, the triaxial creep-seepage experiment was conducted.

2.2. Testing Apparatus. To study the mechanical properties and seepage law in the rheological process of gas-bearing coal, a triaxial creep-seepage-adsorption and desorption experimental device was independently developed by Henan University of Science and Technology [18, 19]. The device is mainly composed of 8 parts, including the main engine, servo loading system, triaxial pressure chamber, pore pressure control system, adsorption and desorption system, temperature control system, deformation measurement system, and safety protection system. The maximum axial pressure is $500 \mathrm{kN}$, the maximum confining pressure is $50 \mathrm{MPa}$, and the maximum heating stability temperature is $900^{\circ} \mathrm{C}$. The size of the specimen is $50 \mathrm{~mm} \times 100 \mathrm{~mm}$. The device has strong function, stable performance, and high accuracy in the test. By adopting the ball screw loading method, it meets the long-term loading requirements of the creep-seepage experiment, and the maximum loading time can reach more than 2 months.

The acoustic emission signal acquisition system [20] uses a full-waveform acoustic emission instrument, which can automatically count and store acoustic emission specimens, record multichannel acoustic emission signals, and synchronously extract acoustic emission signal parameters. The acoustic emission (AE) method can reveal the formation and propagation of microcracks in rock.

\subsection{Experimental Scheme}

(1) Fill the coal sample into the triaxial pressure chamber, apply 704 silica gel to the upper and lower pressure heads and the coal sample wall, wrap the coal sample with a double-layer heat-shrinkable tube, and dry it for more than 10 hours. Load the prepared sample into the seepage device, close the air inlet valve, open the air outlet valve, and remove the impurity gas in the specimen by vacuum extraction.

(2) Load the confining pressure to $8 \mathrm{MPa}$ and the axial pressure to $12 \mathrm{MPa}$, and adjust the test temperature to $25^{\circ} \mathrm{C}$. After the temperature reached the predetermined value, hold the temperature for at least 2 hours. Fill the pipeline with gas with a pressure of 1.4 $\mathrm{MPa}$ and record the pressure after the coal sample is absorbed for more than 12 hours and the pressure gauge reading on the reference cylinder does not change. Subsequently, open the outlet valve and record the gas seepage flow per minute after the gas flow is stable. 

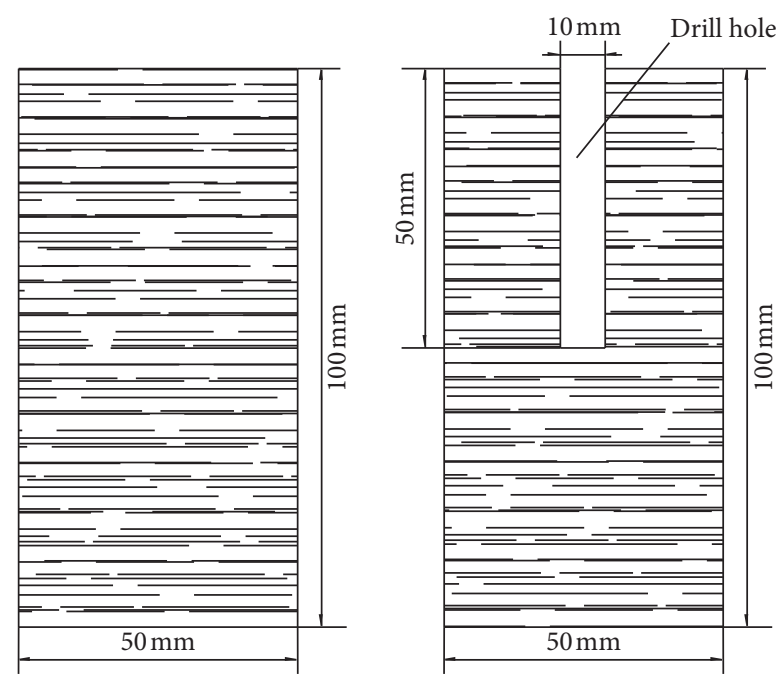

FIGURE 1: Conventional coal sample and porous coal sample.

(3) Gradually change axial stress until the sample failure, and carry out acoustic emission experiments out in the meantime.

(4) Fix the gas pressure at $1.4 \mathrm{MPa}$, and adjust the confining pressure to 6,10 , and $12 \mathrm{MPa}$, respectively. Repeat Steps (1) (3).

(5) Fix the confining pressure at $8 \mathrm{MPa}$, and adjust the gas pressure to $1.0,1.8$, and $2.2 \mathrm{MPa}$, respectively. Repeat Steps (1) (3).

\section{Experimental Study on Mechanical Properties of Porous and Conventional Gas- Bearing Coal Samples}

3.1. Influence of Confining Pressure and Gas Pressure on Peak Strength of Porous and Conventional Gas-Bearing Coal Samples under Triaxial Compression. As one of the physical and mechanical properties of rock, peak strength refers to the maximum axial stress that the rock specimen can resist under the action of triaxial compressive stress. The study of peak strength of rock has practical significance for solving practical problems in mine engineering. Figure 2 shows the variation of peak strength of porous and conventional gasbearing coal samples with confining pressure or gas pressure.

It can be seen from Figure 2 that when the gas pressure was fixed, the compressive resistance of two kinds of gasbearing coal samples increased with the increase of confining pressure; when the confining pressure was fixed, the compressive strength of the two decreased with the increase of gas pressure. When the gas pressure was $1.4 \mathrm{MPa}$ and the confining pressure gradient was $6,8,10$, and $12 \mathrm{MPa}$, the peak strength of both porous and conventional gas-bearing coal samples gradually increased. This is mainly because under the action of confining pressure, the friction between the fracture surfaces of coal samples was strengthened, which inhibited the deformation and failure of coal samples during the loading process, thus improving their compressive ability. When the confining pressure was $8 \mathrm{MPa}$ and the gas pressure gradient was $1.0,1.4,1.8$, and 2.2 $\mathrm{MPa}$, the peak strength of porous and conventional gas-bearing coal samples gradually decreased. This was due to the combined action of free state and adsorbed state gas, which caused the coal sample to undergo expansion deformation, crack expansion, and other microscopic damage, resulting in the reduction of the strength. When the confining pressure and gas pressure were constant, the peak strength of the porous gas-bearing coal sample was relatively smaller, which was $1 /$ 4 less than that of the conventional gas-bearing coal sample.

Linear fitting of the measured data was performed, and the fitting results showed that $R^{2}$ was greater than 0.9 , which shows that there was a good linear relationship between peak strength of two types of gas-bearing coal samples and confining pressure or gas pressure. By only changing the confining pressure, the slope of porous and conventional gas-bearing coal samples was 4.425 and 4.563 , respectively; by only changing the gas pressure, the slope of the two coal samples was -10.139 and -13.601 , respectively. This indicates that when there is only one variable, the peak strength of the two kinds of coal samples shows a consistent trend of change, but the slope of the peak strength of the two is greatly different under the influence of gas pressure alone.

3.2. Influence of Confining Pressure and Gas Pressure on Peak Strain of Porous and Conventional Gas-Bearing Coal Samples under Triaxial Compression. The strain when the coal sample reaches peak strength is called peak strain. Figure 3 shows the variation of peak strain of porous and conventional gas-bearing coal samples with confining pressure or gas pressure. It can be seen from the figure that when the confining pressure was fixed, the peak strain of the two kinds of gas-bearing coal samples increased gradually with the increase of gas pressure; when the gas pressure was fixed, the peak strain of two kinds of gas-bearing coal samples increased with the increase of confining pressure; when the confining pressure and gas pressure are both fixed, the peak strain of porous gas-bearing coal sample was relatively smaller, which was reduced by two-thirds at most.

Linear fitting of the measured data was performed, and the fitting results showed that $R^{2}$ was greater than 0.9 , which shows that the peak strain of two kinds of gas-bearing coal samples showed a good linear relationship with confining pressure or gas pressure. When only confining pressure was changed, and the slope of porous and conventional gasbearing coal samples was 0.000295 and 0.00028 , respectively; when only gas pressure was changed, the slope of the two coal samples was 0.00074 and 0.00154 , respectively. It shows that the peak strain of two kinds of gas-bearing coal samples shows a consistent trend of change when there is only one variable, but the slope of peak strain of two is greatly different under the influence of gas pressure alone.

3.3. Effects of Confining Pressure and Gas Pressure on Elastic Modulus of Porous and Conventional Gas-Bearing Coal Samples under Triaxial Compression. At the elastic deformation stage, the stress and strain are in a proportion relation; that is, the stress-strain relation conforms to Hooke's 


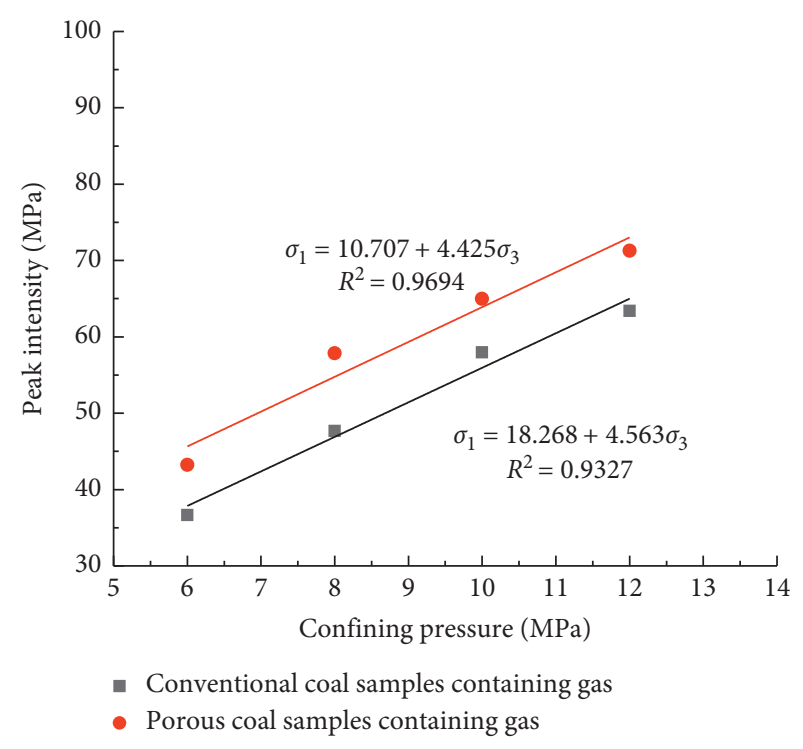

(a)

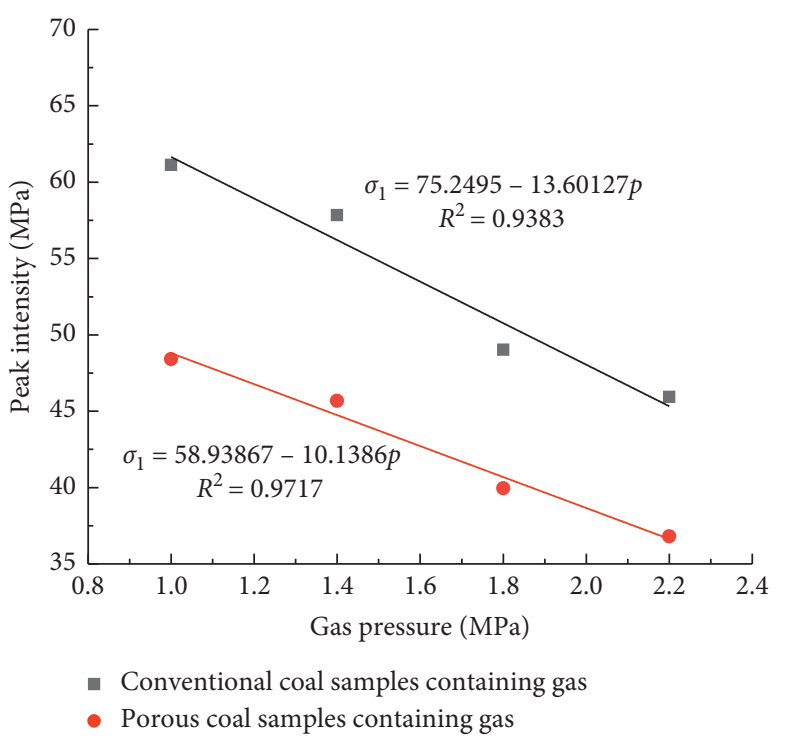

(b)

FIGURE 2: The variation of peak strength of porous and conventional gas-bearing coal samples with confining pressure or gas pressure: (a) variation with confining pressure; (b) variation with gas pressure change.

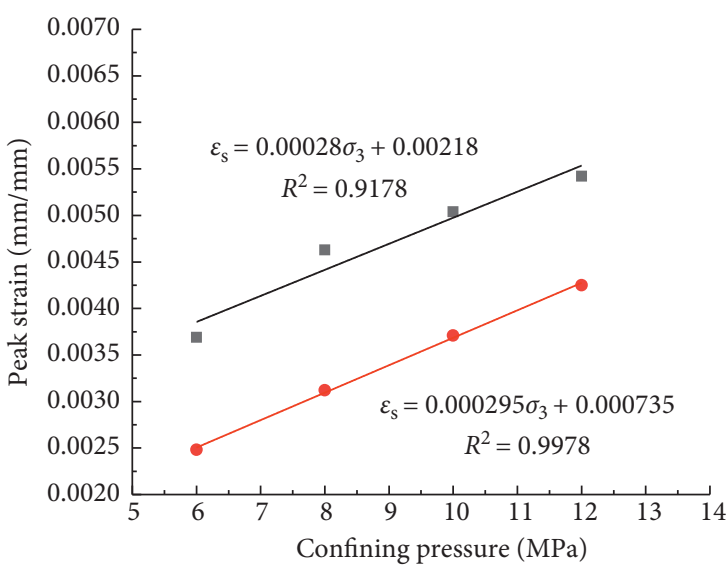

- Conventional coal samples containing gas

- Porous coal samples containing gas

(a)

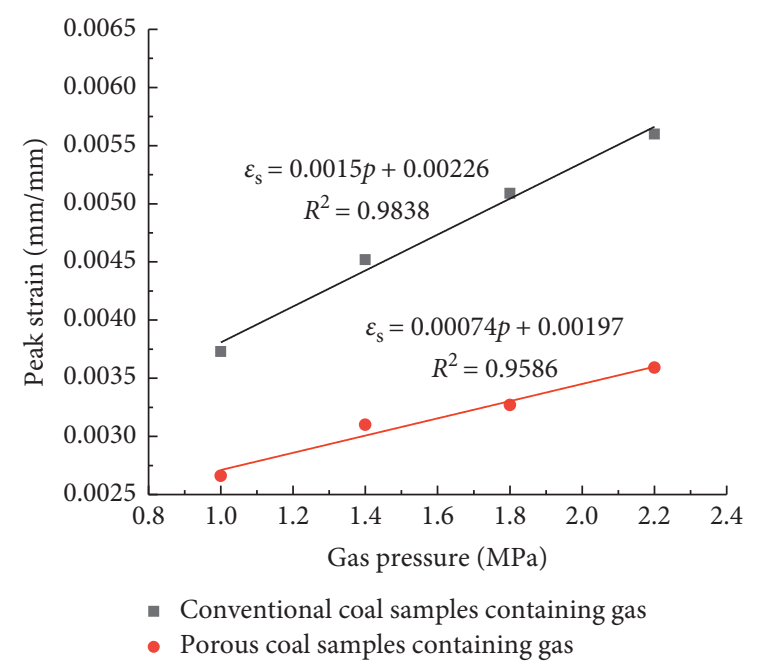

(b)

FIGURE 3: Variation of peak strain of porous and conventional gas-bearing coal samples with confining pressure or gas pressure: (a) variation with confining pressure; (b) variation with gas pressure change.

law, and its proportional coefficient is called elastic modulus. The change of elastic modulus of rock with confining pressure or gas pressure is closely related to the defects and density degree inside rock. Figure 4 shows the variation of peak strain of porous and conventional gas-bearing coal samples with confining pressure or gas pressure.

It can be seen from the Figure 4 that when gas pressure was fixed, the elastic modulus of conventional or porous gasbearing coal samples gradually increased with the increase of confining pressure, which is due to that the increase of confining pressure made the cracks and pores in the rock sample compressed and closed, increasing the stiffness of the rock. When the confining pressure was fixed, the elastic modulus of conventional or porous gas-bearing coal decreased with the increase of gas pressure. This is due to the fact that the increase of gas pressure made the gas with a certain kinetic energy continuously enter the pores and fractures in the coal sample through seepage, and adhere to the surface of coal particles through adsorption, reducing the surface energy of coal matrix and the bonding force between coal matrices, leading to enlarged spacing between the coal particles [21]. When the confining pressure and gas pressure were both fixed, the elastic modulus of porous gas-bearing coal sample was relatively larger, which was increased by $3 / 4$ at most.

The data measured in the experiment were fitted exponentially, and the fitting results showed that $R^{2}$ was 


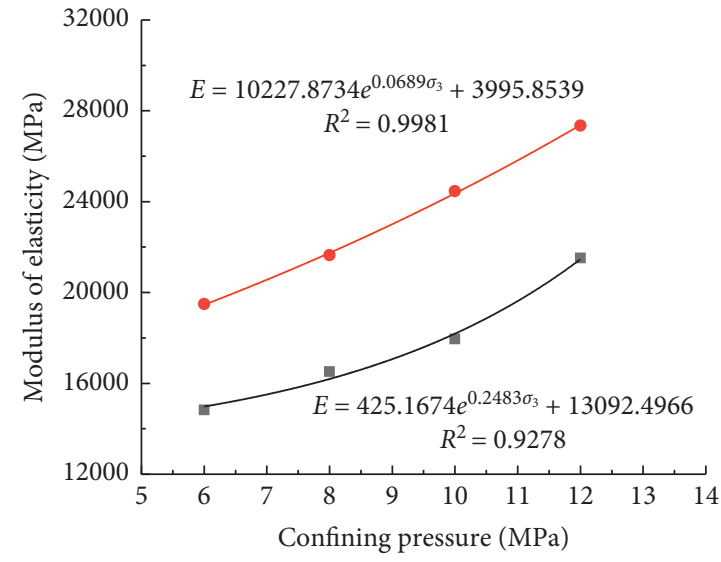

- Conventional coal samples containing gas

- Porous coal samples containing gas

(a)

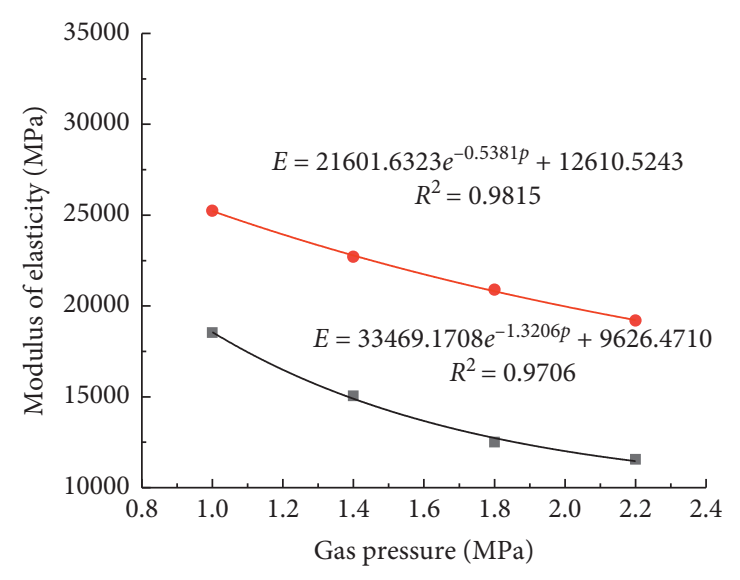

- Conventional coal samples containing gas

- Porous coal samples containing gas

(b)

FIGURE 4: The variation of elastic modulus of porous and conventional gas-bearing coal samples with confining pressure or gas pressure: (a) variation with confining pressure; (b) variation with gas pressure change.

greater than 0.9 , indicating that there was a good exponential relation between the elastic modulus of two kinds of coal samples and the confining pressure or gas pressure. When only the confining pressure was changed, and the indexes of porous and conventional gas-bearing coal samples were 0.0689 and 0.2483 , respectively; when only the gas pressure was changed, and the indexes of porous and conventional gas-bearing coal samples were -0.5381 and -1.3206 , respectively. It shows that the elastic modulus of the two kinds of gas-bearing coal samples shows a consistent change trend when there is only one variable, but the elastic modulus of the two kinds of gas-bearing coal samples differs greatly under the influence of confining pressure alone.

\section{Experimental Study on Permeability Characteristics of Porous and Conventional Gas-Bearing Coal Samples}

In the seepage experiment of gas-bearing coal, the influence of temperature was ignored, and the gas seepage in coal sample was assumed to conform to Darcy's law [22]. According to the experimental results of gas-bearing coal, the permeability of coal sample can be calculated by the following formula [23-25]:

$$
k=\frac{2 q e p e \mu L}{\left(p i^{2}-p e^{2}\right) S s p},
$$

where $k$ is the permeability, $\mathrm{mD} ; q_{e}$ is the gas seepage flow under standard condition, $\mathrm{cm}^{3} / \mathrm{s} ; L$ is the sample length, $\mathrm{cm}$; $\mu=1.08 \times 10^{-5} \mathrm{~Pa}$.s is the dynamic viscosity of gas; $S_{s p}$ is the cross-sectional area of the sample, $\mathrm{cm}^{2} ; p_{e}$ is the gas outlet pressure, $\mathrm{Pa}$; and $p_{i}$ is the gas inlet pressure, $\mathrm{Pa}$.

The seepage experiments of gas-bearing coal under the condition of fixing gas pressure while changing confining pressure or fixing confining pressure while changing gas pressure were carried out. According to the above formula, the seepage experimental results of gas-bearing coal under various stress conditions can be obtained, as shown in Table 1.

4.1. Experimental Study on the Influence of Confining Pressure on Permeability Characteristics of Porous and Conventional Gas-Bearing Coal Samples. According to the experimental data, the variation of permeability of porous and conventional gas-bearing coal samples with the confining pressure when the fixed gas pressure is $1.4 \mathrm{MPa}$ can be obtained, as shown in Figure 5.

It can be seen from Figure 5 that when gas pressure was fixed, the permeability of two kinds of gas-bearing coal samples decreased with the increase of confining pressure, which conforms to the permeability variation law in mining engineering. This is because when the coal body was under load, the pores and cracks in the coal were closed, so the permeability decreased [26]. Under fixed confining pressure, the permeability of porous gas-bearing coal sample was relatively higher, which is mainly due to that the existence of pores directly increased the porosity of coal and rock mass, resulting in accelerated gas flow and increased permeability.

In mining engineering, the influence of mine pressure on the permeability of coal seam was as follows: the permeability of coal seam increased in the pressure relief area of coal seam and decreased in the stress concentration area. Therefore, the relationship between crustal stress and coal permeability should be taken into account when gas drainage and taking relevant measures to avoid disasters related with methane and coal, to achieve better results. At the same time, the influence of drilling borehole on coal permeability cannot be ignored. Due to the construction of the drilling borehole, the stress condition around the borehole changes, and the stress field was redistributed and a new balance was generated. In this process, the elastic modulus and other mechanical parameters of the coal around the borehole will change accordingly, the strength of 
TABLE 1: Experimental results of seepage of porous and conventional gas-bearing coal samples.

\begin{tabular}{lccc}
\hline $\begin{array}{l}\text { Type of coal } \\
\text { sample }\end{array}$ & $\begin{array}{c}\text { Gas } \\
\text { pressure } \\
(\mathrm{MPa})\end{array}$ & $\begin{array}{c}\text { Confining } \\
\text { pressure } \\
(\mathrm{MPa})\end{array}$ & $\begin{array}{c}\text { Permeability } \\
(\mathrm{mD})\end{array}$ \\
\hline Conventional & 1.0 & 8 & 2.95 \\
gas-bearing & 1.4 & 8 & 2.65 \\
coal samples & 1.8 & 8 & 3.05 \\
\hline & 2.2 & 8 & 3.16 \\
\hline Porous gas-bearing & 1.0 & 8 & 3.44 \\
coal samples & 1.4 & 8 & 3.20 \\
& 1.8 & 8 & 3.47 \\
Conventional & 2.2 & 8 & 3.66 \\
gas-bearing & 1.4 & 6 & 3.32 \\
coal samples & 1.4 & 8 & 2.48 \\
& 1.4 & 10 & 1.76 \\
Porous gas-bearing & 1.4 & 12 & 1.07 \\
coal samples & 1.4 & 6 & 4.30 \\
& 1.4 & 8 & 3.20 \\
\hline
\end{tabular}

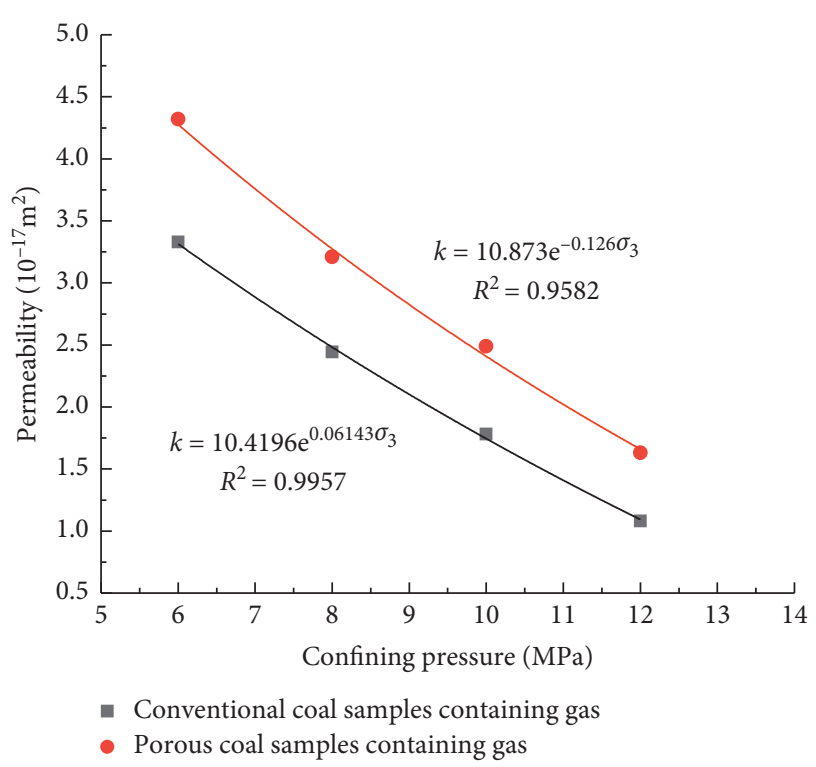

FIGURE 5: Change of permeability of porous and conventional gasbearing coal samples with confining.

the coal will weaken, the number of pores and fractures will increase, and finally the permeability of the coal around the borehole will increase. It is not difficult to see from Figure 5 that drilling borehole has a great impact on the permeability of nearby coal, and the porous gas-bearing coal sample increases nearly twice as much as that of the conventional gas-bearing coal sample.

According to the shape of the curve in Figure 5, the nonlinear regression was carried out, and the relationship between permeability of two kinds of gas-bearing coal samples and confining pressure could be fitted by exponential function, $k=a 2 e^{b_{2} \sigma_{3}}$, where $a 2$ and $b 2$ are the regression coefficients.
The fitting equation of conventional gas-bearing coal sample is $k=10.4196 e^{-0.0614 \sigma 3}$, where the correlation coefficient $R^{2}=0.9957$;

The fitting equation of porous gas-bearing coal sample is $k=10.873 e^{-0.126 \sigma_{3}}$, where the correlation coefficient $R^{2}=0.9582$;

It can be seen that the fitting results are in good agreement with the experimental results, which is consistent with the research results in reference [27].

4.2. Experimental Study on the Influence of Gas Pressure on Permeability Characteristics of Porous and Conventional GasBearing Coal Samples. According to the experimental data, the permeability of porous and conventional gas-bearing coal samples changed with gas pressure when the confining pressure was fixed as $8 \mathrm{MPa}$, as shown in Figure 6 .

It can be seen from Figure 6 that, under fixed confining pressure, the permeability of the two kinds of gas-bearing coal samples exhibited a change trend of decreasing first and then increasing with the increase of gas pressure. When the gas pressure increases to about $1.4 \mathrm{MPa}$, the permeability of the two kinds of gas-bearing coal samples reaches the lowest value. Before the gas pressure rises to the critical value, the Klinkenberg effect [28] dominates. With the increase of gas pressure, the adsorption amount of gas on coal samples increases, and the Klinkenberg effect gradually strengthens, which affects the effective permeability of gas in coal samples, thus leading to the decrease of permeability. With the increase of gas pressure, the occurrence and development of internal cracks in the coal body were promoted, and the driving force for gas penetration from coal samples was also increasing [29]. Therefore, permeability started to rise and maintained the trend of growth. At the same time, the permeability of the porous gas-bearing coal sample was higher than that of conventional gas-bearing coal samples, which is due to the fact that the existing pores increased the porosity of coal rock mass, and the drilling operation also increased the number of cracks in coal rock mass.

\section{Experimental Study on Acoustic Emission Characteristics of Porous and Conventional Gas-Bearing Coal Samples in the Whole Stress-Strain Process}

In the process of coal mining, the coal body is in the state of triaxial stress, and the deformation and failure of coal samples will show under load. These deformations are caused by the adjustment of pores and fractures in the coal sample, the adjustment of particle positions, and the deformation and failure of particles. Therefore, acoustic emission characteristics can be used to judge the deformation and failure of coal samples [30], and then predict the occurrence of outburst accidents of coal and gas based on the deformation and failure of coal samples.

This experiment was conducted using the ringing count method, and the synchronization of load and sound emission signal measurement was guaranteed. According to the test, the test results are summarized as shown in Table 2. Figures 7 and 8 show acoustic emission characteristic charts 


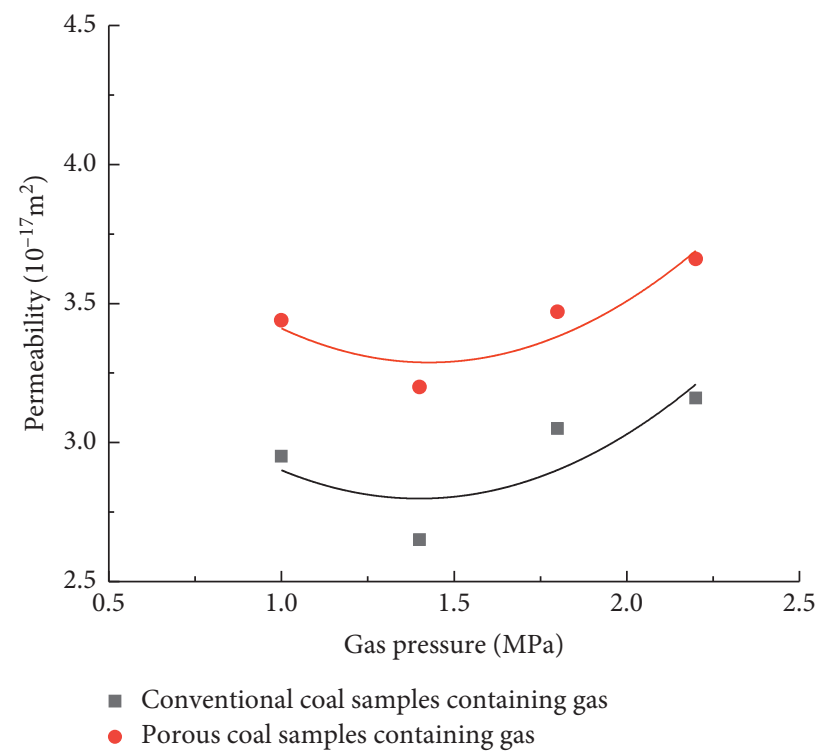

FIgURE 6: Changes of permeability of conventional and porous gas-bearing coal samples.

TABLE 2: Acoustic emission parameters of porous and conventional gas-bearing coal samples under different confining pressures and gas pressures.

\begin{tabular}{|c|c|c|c|c|c|c|c|}
\hline \multirow{2}{*}{$\begin{array}{l}\text { Confining pressure } \\
(\mathrm{MPa})\end{array}$} & \multirow{2}{*}{$\begin{array}{l}\text { Gas pressure } \\
(\mathrm{MPa})\end{array}$} & \multicolumn{2}{|c|}{$\begin{array}{c}\text { Maximum ringdown } \\
\text { count }\end{array}$} & \multicolumn{2}{|c|}{ Maximum energy (J) } & \multicolumn{2}{|c|}{ Maximum amplitude $(\mathrm{dB})$} \\
\hline & & Conventional & Porous & Conventional & Porous & Conventional & Porous \\
\hline 6 & 1.4 & 25832 & 19735 & 63269 & 44820 & 93 & 91 \\
\hline 8 & 1.4 & 17883 & 13998 & 45535 & 35700 & 95 & 93 \\
\hline 10 & 1.4 & 14241 & 8176 & 35960 & 22895 & 98 & 96 \\
\hline 12 & 1.4 & 5407 & 3244 & 23001 & 12017 & 99 & 97 \\
\hline 8 & 1.0 & 24583 & 17308 & 74692 & 43129 & 92 & 89 \\
\hline 8 & 1.8 & 14586 & 11899 & 39153 & 30443 & 97 & 95 \\
\hline 8 & 2.2 & 12715 & 10246 & 36920 & 27745 & 99 & 98 \\
\hline
\end{tabular}
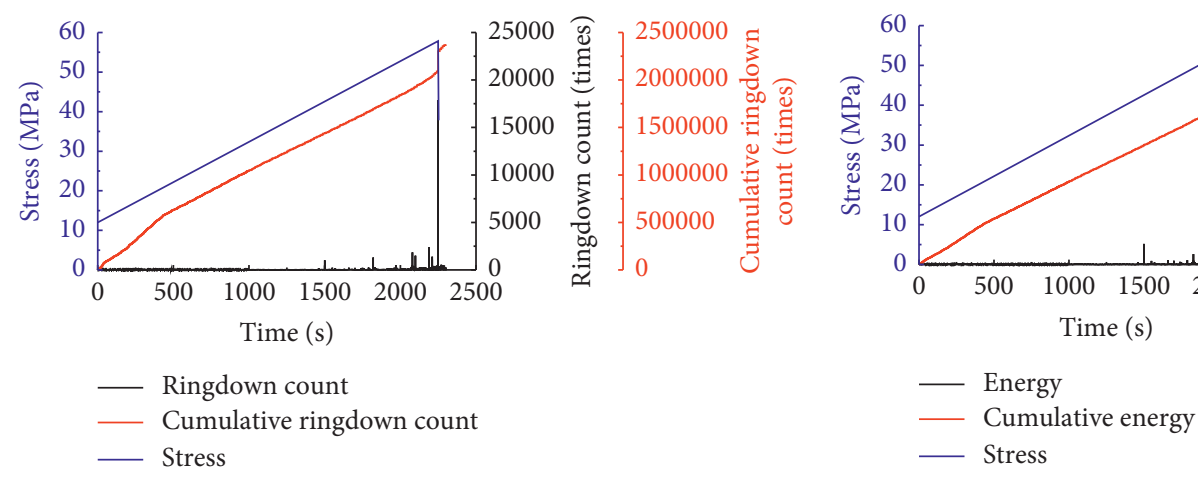

(a)

Figure 7: Continued. 


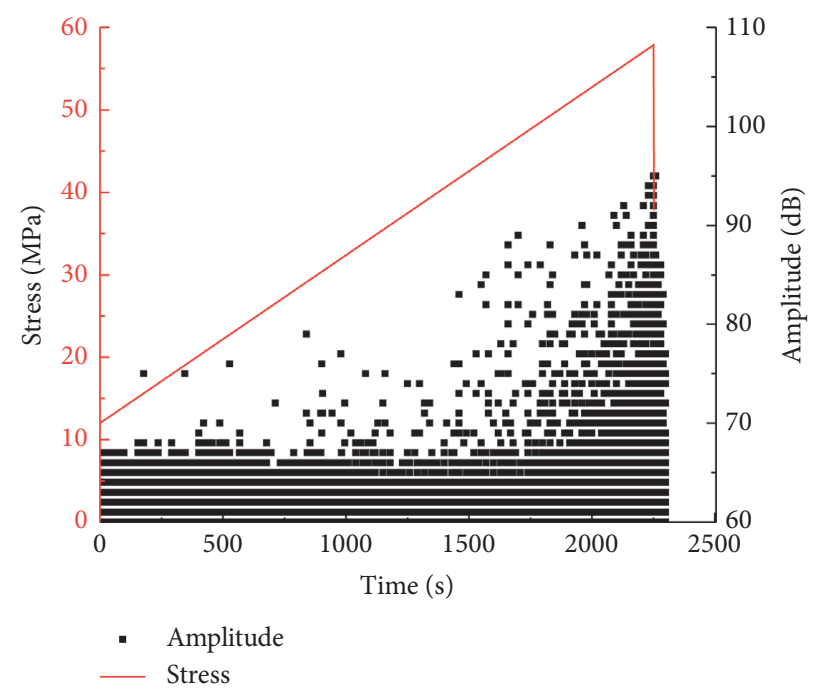

(c)

Figure 7: Acoustic emission characteristic map of the conventional gas-bearing coal sample: (a) stress-ringdown count-cumulative counttime; (b) stress-energy-cumulative energy-time; (c) stress-amplitude-time.

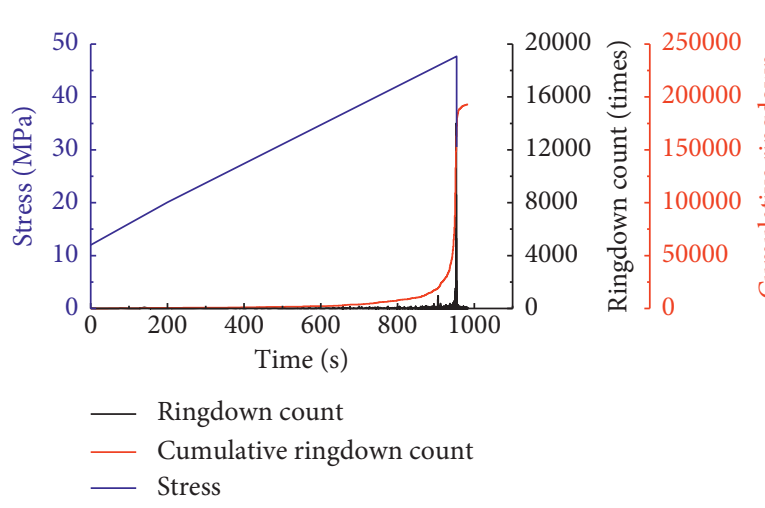

(a)

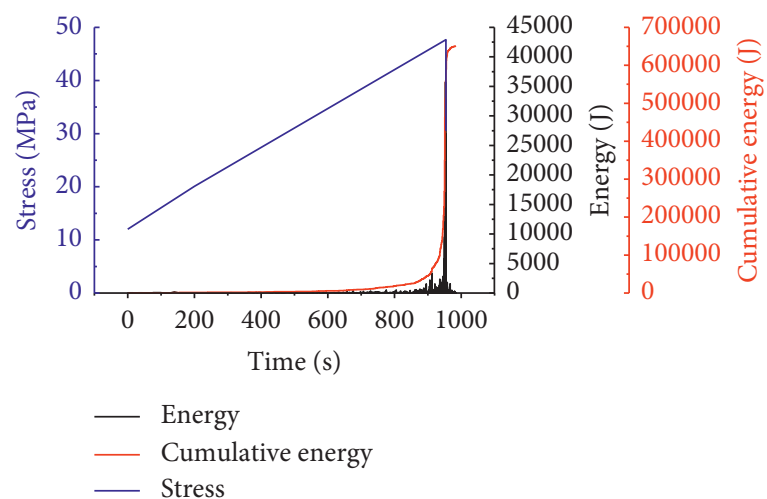

(b)

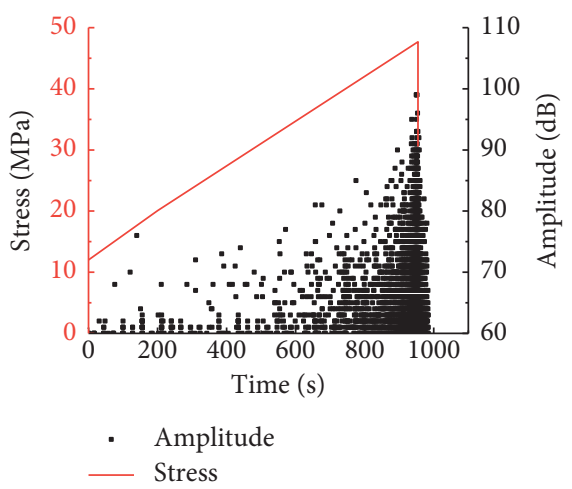

(c)

Figure 8: Acoustic emission characteristic map of the porous gas-bearing coal sample: (a) stress-ringdown count-cumulative count-time; (b) stress-energy-cumulative energy-time; (c) stress-amplitude-time.

of porous and conventional gas-bearing coal samples with a confining pressure of $8 \mathrm{MPa}$ and gas pressure of $1.4 \mathrm{MPa}$, respectively.
According to the stress-strain curve and the change law of acoustic emission parameters of coal samples with time, acoustic emission characteristics of coal samples in the 
process of loading failure can be divided into four stages [31], namely, initial stage, stationary stage, active stage, and residual stage of acoustic emission.

There were some similarities and differences in the acoustic emission characteristics between conventional and porous gas-bearing coal samples. The similarities lied in that the ringdown count, energy, and amplitude of acoustic emission events in the initial stage are low, and the sharp rise of ringdown count, energy, and amplitude occurred occasionally. In the stable stage of acoustic emission, the trend of acoustic emission was relatively stable, and the ringdown count, energy, and amplitude of acoustic emission events increased correspondingly. In the active stage of acoustic emission, the acoustic emission ringdown count increased sharply in the early stage, and the energy and amplitude also increased correspondingly. When the failure of coal occurred, the deformation increased and the cracks increasingly propagated and connected, and then the acoustic emission ringdown counts were very large and the energy and amplitude were very high. The maximum ringdown count, energy, and amplitude of the coal sample appeared near the intensity peak at this stage. In the residual stage of acoustic emission, there were still a few acoustic emission activities, but the ringdown count and energy were low and the amplitude decreased sharply. The maximum ringdown count of the porous gas-bearing coal sample can be reduced by one-third at most, the maximum energy can be reduced by nearly half at most, and the maximum amplitude changes little with only $1-3 \mathrm{~dB}$ reduction. The main reason is that the porous gas-bearing coal sample has a weak resistance to deformation and a low difficulty in damage expansion, which makes the porous gas-bearing coal sample deform faster and accumulate less deformation energy before failure.

\section{Conclusions}

(1) When fixing gas pressure while changing confining pressure, the porous gas-bearing coal sample has higher peak strength and elastic modulus but lower peak strain. When fixing confining pressure while changing gas pressure, the porous gas-bearing coal sample has lower peak strength and peak strain, but higher elastic modulus. The peak strength and strain of two kinds of gas-bearing coal samples have a good linear relationship with confining pressure or gas pressure, and the slopes of peak strength and strain of two kinds of coal samples under the influence of gas pressure are significantly different. The elastic modulus of two kinds of gas-bearing coal samples have a good exponential relationship with confining pressure or gas pressure, and the indices of elastic modulus of two kinds of coal samples under the influence of confining pressure are significantly different. The pores have an important influence on the mechanical failure characteristics of coal rock mass and have important guiding significance for the study of coal roadway stability and development of protection technology.
(2) When the gas pressure is fixed at $1.4 \mathrm{MPa}$, the permeability of two kinds of gas-bearing coal samples decreases with the increase of confining pressure; when the confining pressure is fixed at $8 \mathrm{MPa}$, the permeability of two kinds of coal samples first decreases and then increases with the increase of gas pressure, indicating that the gas pressure of $1.4 \mathrm{MPa}$ is the critical point where the Klinkenberg effect loses its dominant role. When the confining pressure and gas pressure are both fixed, the permeability of the porous gas-bearing coal sample is higher than that of the conventional gas-bearing coal sample. The pores have an important influence on the permeability of coal and rock, which is helpful to improve the development and utilization of deep coalbed methane in the mine area.

(3) In the whole stress-strain process, compared with the conventional gas-bearing coal sample, the maximum ringdown count of the porous gas-bearing coal sample can be reduced by one-third at most, the maximum energy can be reduced by nearly half at most, and the maximum amplitude changes little with only $1-3 \mathrm{~dB}$ reduction, indicating a big difference in the acoustic emission characteristics between two kinds of gas-bearing coal samples. Acoustic emission characteristics can be used to predict the occurrence of coal and gas outburst accidents in coal seams under drilling operation.

\section{Data Availability}

All the data used to support the findings of this study are available from the corresponding author upon request.

\section{Conflicts of Interest}

The authors declare that they have no conflicts of interest.

\section{Acknowledgments}

This study was supported by the National Key Research and Development Program of China (grant no. 2018YFC0808103), the National Natural Science Foundation of China (grant nos. 51734007, 51704099, and 52074106), the Program for Innovative Research Team in University of Ministry of Education of China (grant no. IRT_16R22), Key Scientific Research Projects in Colleges and Universities in Henan (grant no. 19A440003), the Doctoral Fund of Henan Polytechnic University (grant no. B2019-56), and the Fundamental Research Funds for the Universities of Henan Province (grant no. NSFRF180338).

\section{References}

[1] L. Yuan, "Strategic thinking of simultaneous exploitation of coal and gas in deep mining," Journal of China Coal Society, vol. 41, no. 1, pp. 1-6, 2016.

[2] L. Jun, Y. Guangzhi, G. Heng et al., "Experimental study on compound dynamic disaster and drilling pressure relief of 
gas-bearing coal under true triaxial loading," Journal of China Coal Society, vol. 45, no. 5, pp. 1812-1823, 2020.

[3] L. Tong, L. Baiquan, X. Wu et al., "A safe mining approach for deep outburst coal seam groups with hard-thick sandstone roof: Stepwise risk control based on gas diversion and extraction," Energy Science \& Engineering, vol. 8, no. 8, pp. 2946-2965, 2020.

[4] T. Zongqing, Y. Shengqiang, X. Guang, and M. Sharifzadeh, "Disaster-causing mechanism and risk area classification method for composite disasters of gas explosion and coal spontaneous combustion in deep coal mining with narrow coal pillars," Process Safety and Environmental Protection, no. 2, pp. 182-188, 2019.

[5] L. Jun, Y. Guangzhi, L. Xing et al., "Deformation and $\mathrm{CO}_{2}$ gas permeability response of sandstone to mean and deviatoric stress variations under true triaxial stress conditions," Tunnelling and Underground Space Technology Incorporating Trenchless Technology Research, vol. 84, pp. 259-272, 2019.

[6] Z. Xiao-Ping and L. N. Y. Wong, "Cracking processes in rocklike material containing a single flaw under uniaxial compression: A numerical study based on parallel bonded-particle model approach," Rock Mechanics and Rock Engineering, vol. 45, no. 5, pp. 711-737, 2012.

[7] L. Diyuan, L. Xibing, L. Chunlin et al., "Experimental and numerical studies of mechanical response of plate-shape granite samples containing prefabricated holes under uniaxial compression," Chinese Journal of Rock Mechanics and Engineering, vol. 30, no. 6, pp. 1198-1206, 2011.

[8] C. H. Park and A. Bobet, "Crack initiation, propagation and coalescence from frictional flaws in uniaxial compression," Engineering Fracture Mechanics, vol. 77, no. 14, 2010.

[9] C. A. Tang, R. H. C. Wong, K. T. Chau, and P. Lin, "Modeling of compression-induced splitting failure in heterogeneous brittle porous solids," Engineering Fracture Mechanics, vol. 72, no. 4, pp. 597-615, 2004.

[10] Y. Shengqi, J. Hongwen, and X. Tao, "Mechanical behavior and failure analysis of brittle sandstone specimens containing combined flaws under uniaxial compression," Central South University, vol. 21, no. 5, pp. 2059-2073, 2014.

[11] Y. Shengqi, L. Xiangru, and L. Yushou, "Experimental analysis of mechanical behavior of sandstone containing hole and fissure under uniaxial compression," Chinese Journal of Rock Mechanics and Engineering, vol. 31, no. S2, pp. 3539-3546, 2012.

[12] L. Zhaowei and L. Yuanhai, "Experimental investigation on the deformation and crack behavior of rock specimen with a hole undergoing uniaxial compressive load," Engineering Mechanics, vol. 27, no. 08, pp. 133-139, 2010.

[13] C. Long, Y. Shengqi, and L. Xiangru, "Experimental and numerial investigation on crack expansion of sandstone containing flaws," Journal of Mining \& Safety Engineering, vol. 29, no. 5, pp. 719-724, 2012.

[14] L. Diyuan, C. Tengjiao, Z. Tao et al., "Experimental study on the dynamic strength and fracturing characteristics of marble specimens with a single hole under impact loading," Chinese Journal of Rock Mechanics and Engineering, vol. 34, no. 2, pp. 249-260, 2015.

[15] M. Shaopeng, W. Laigui, and Z. Yonghong, "Experimental study on deformation field evolution during failure procedure of a rock borehole structure," Rock and Soil Mechanics, no. 7, pp. 1082-1086, 2006.

[16] Z. Yangsheng, Y. Baoping, W. Zhiyun et al., "Study of critical condition of borehole instability in granite under high temperature and pressure," Chinese Journal of Rock Mechanics and Engineering, vol. 28, no. 5, pp. 865-874, 2009.

[17] S. Zehong, Y. Xiangrong, T. Min et al., "Study on data simulation and boring method of borehole deformation instability in deep soft rock strata," Zhongzhou Coal, no. 7, pp. 13-16, 2011.

[18] W. Dengke, P. Ming, W. Jianping et al., "Experimental investigation of gas desorption law of loaded raw coal," Journal of China Coal Society, vol. 41, no. 3, pp. 644-652, 2016.

[19] W. Dengke, P. Ming, W. Jianping et al., "Development and application of tri-axial creep-seepage-adsorption and desorption experimental device for coal," Coal Geology \& Exploration, vol. 44, no. 3, pp. 10-13, 2016.

[20] Z. Yu, Study on Acoustic Emission Characteristics of Rock Failure Process in Coal Mine under Uniaxial Compression, Anhui University of Science and Technology, Huainan, China, 2015.

[21] G. Baobin, L. Pengbo, and G. Fang, "Study on mechanical properties and acoustic emission characteristics of coal at different gas pressure," Coal Science and Technology, vol. 46, no. 1, pp. 112-119, 2018.

[22] C. Yapei, S. Haitao, and Z. Dongming, "Experimental study on evolution in the characteristics of permeability, deformation, and energy of coal containing gas under triaxial cyclic loading-unloading," Energy Science \& Engineering, vol. 7, no. 5, pp. 2112-2123, 2019.

[23] ASTM Standard D4525, Standard Test Method for Permeability of Rocks by Flowing Air, American Society for Testing Materials, West Conshohocken, PA, USA, 1990.

[24] W. Fakai, H. Jiangfu, L. Yunpei, Y. Luo, Z. Liao, and L. Li, "Study on the permeability characteristics of coal containing coalbed methane under different loading paths," Energy Science \& Engineering, vol. 6, no. 5, pp. 475-483, 2018.

[25] W. Dengke, L. Ruihuan, P. Ming, P. Zhang, C. Yu, and B. Yao, "Experimental study on anisotropic permeability rule of coal bearing methane," Journal of China Coal Society, vol. 43, no. 4, pp. 1008-1015, 2018.

[26] Y. Zhilong, Study on Unstable Failure Characteristics of Coalbed Borehole Based on Hoek-Brown Criterion, Henan Polytechnic University, Jiaozuo, China, 2013.

[27] Z. Shining and L. Boquan, Theory of Gas Occurrence and Flow in Coal Seam, China Coal Industry Publishing House, Beijing, China, 1997.

[28] W. Dengke, Research on Constitutive Models and Instability Rules of Gas-Saturated Coal, Chongqing University, Chongqing, China, 2009.

[29] D.-d. Zhang, Experimental Study on Mechanical Characteristics and Seepage Characteristics of Coal Containing Methane under the Coupling Effect between Stress and Thermal, Chongqing University, Chongqing, China, 2011.

[30] Z. Hongbao, Theoretical and Experimental Study on Unsable Falure and AE Characteristics of Coal Contained Gas, Chongqing University, Chongqing, China, 2009.

[31] C. Chunjian, Experimental Study on Seepage and Acoustic Emission Characteristics of Coal and Rock under ThermoMechanical Coupling Action, Taiyuan University of technology, Taiyuan, China, 2019. 